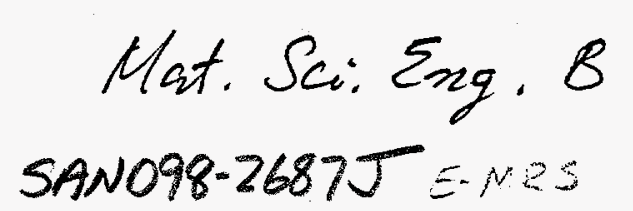

\title{
Comparison of ICl- and IBr-Based Plasma Chemistries for Inductively Coupled Plasma Etching of GaN, InN and AIN
}

Y. B. Hahn $n^{(1)^{*}}$, D. C. Hays ${ }^{(1)}$, H. Cho ${ }^{(1)}$, K. B. Jung ${ }^{(1)}$, C. R. Abernathy ${ }^{(1)}$, S. M. Donovan $^{(1)}$, S. J. Pearton ${ }^{(1)}$, J. Han ${ }^{(2)}$ and R. J. Shul ${ }^{(2)}$

(1) Department of Materials Science and Engineering, University of Florida, Gainesville, FL 32611.

(2) Sandia National Laboratories, Albuquerque, NM 87185.

ABSTRACT

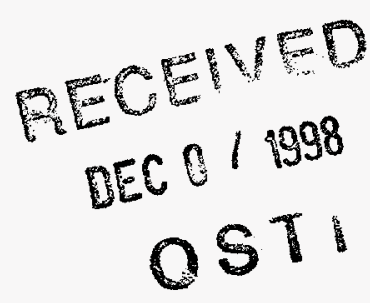

A parametric study of the etch characteristics of GaN, AIN and InN has been carried out with ICV/Ar and $\mathrm{IBr} / \mathrm{Ar}$ chemistries in an Inductively Coupled Plasma discharge. The etch rates of $\mathrm{InN}$ and AlN were relatively independent of plasma composition, while $\mathrm{GaN}$ showed increased etch rates with interhalogen concentration. Etch rates for all materials increased with increasing rf chuck power, indicating that higher ion bombardment energies are more efficient in enhancing sputter desorption of etch products. The etch rates increased for source powers up to $500 \mathrm{~W}$ and remained relatively thereafter for all materials, while $\mathrm{GaN}$ and $\mathrm{InN}$ showed maximum etch rates with increasing pressure. The etched $\mathrm{GaN}$ showed extremely smooth surfaces, which were somewhat better with $\mathrm{IBr} / \mathrm{Ar}$ than with ICl/Ar. Maximum selectivities of $\sim 14$ for $\operatorname{InN}$ over $\mathrm{GaN}$ and $>25$ for InN over AlN were obtained with both chemistries.

* Present address: Department of Chemical Engineering and Technology, Chonbuk National University, Chonju 561-756, Korea. 


\section{DISCLAIMER}

This report was prepared as an account of work sponsored by an agency of the United States Government. Neither the United States Government nor any agency thereof, nor any of their employees, make any warranty, express or implied, or assumes any legal liability or responsibility for the accuracy, completeness, or usefulness of any information, apparatus, product, or process disclosed, or represents that its use would not infringe privately owned rights. Reference herein to any specific commercial product, process, or service by trade name, trademark, manufacturer, or otherwise does not necessarily constitute or imply its endorsement, recommendation, or favoring by the United States Government or any agency thereof. The views and opinions of authors expressed herein do not necessarily state or reflect those of the United States Government or any agency thereof. 


\section{DISCLAIMER}

Portions of this document may be illegible in electronic image products. Images are produced from the best available original document. 


\section{INTRODUCTION}

Plasma etching techniques have been predominantly used in the patterning of IIInitrides for photonic devices such as laser diodes and light-emitting diodes (LEDs). ${ }^{1-12}$ Currently, all of the LEDs and a majority of the lasers are ridge wave guide structures in which the mesas are formed by dry etching. ${ }^{13}$ Therefore, most of the previous etching studies have been focused on obtaining the relatively large etch depths $(2-4 \mu \mathrm{m})$ typical of ridge or facet heights, where the final surface morphology on the field is less important. Moreover, an n-type ohmic contact is deposited on the etched surface, and loss of nitrogen from this surface actually improves contact resistance. Attention is now turning to the development of GaN-based high power/high temperature electronics for power switching and transmission applications. ${ }^{14-18}$ In these devices, the etch depth is much shallower, but smooth morphologies and high selectivities for InN over the other nitrides are required because layers based on $\mathrm{InN}$ will probably be used to obtain low ohmic contact resistance. In some cases rectifying contact will be deposited on the etched surface, so its electrical quality is most important.

Shul et al. ${ }^{1,10}$ reported Inductively Coupled Plasma (ICP) etching of GaN, AlN, InN, InAlN and InGaN at low dc biases ( $\leq-100 \mathrm{~V}$ ) with $\mathrm{Cl}_{2}, \mathrm{CH}_{4} / \mathrm{H}_{2}, \mathrm{Cl}_{2} / \mathrm{Ar}, \mathrm{Cl}_{2} / \mathrm{N}_{2}$ and $\mathrm{Cl}_{2} / \mathrm{H}_{2}$ plasma chemistries. They controlled the etch rates in the range of $500 \sim 1500$ $\AA / \mathrm{min}$ for electronic device structures, and obtained maximum etch selectivities of $\sim 6$ at higher ICP source powers $(850 \mathrm{~W})$ for InN over the other nitrides. Alternative chemistries have included $\mathrm{IBr}^{19}$ and $\mathrm{ICl}_{1}{ }^{20}$ operated under Electron Cyclotron Resonance conditions. These interhalogens appear to be readily dissociated, producing high 
concentrations of reactive chlorine, bromide and iodine. However, no work has been done on the ICP etching of III-nitrides with ICl- and IBr-based plasma chemistries. The ICP configuration is the preferred one for high density etching because of its superior uniformity, control and lower cost of ownership.

In this paper, a parametric study of ICP etching of GaN, AIN and InN with ICland $\mathrm{IBr}$-based plasma chemistries is reported. The effects of plasma composition, if chuck power and ICP source power on etch rates, etch yield, selectivity, dc biases and ion flux at the sheath edge have been investigated. There is no clear advantage in terms of etch rates or selectivity for either chemistry. The ICP discharges are well suited for achieving controllable etch rates (500 - $1500 \AA / \mathrm{min}$ ) and high selectivities (up to 30 ) for InN over $\mathrm{AIN}$ and $\mathrm{GaN}$.

\section{EXPERIMENTAL}

The AlN and InN samples were grown by Metal Organic Molecular Beam Epitaxy (MOMBE) on $\mathrm{Al}_{2} \mathrm{O}_{3}$ substrates at $800{ }^{\circ} \mathrm{C}$ and $575{ }^{\circ} \mathrm{C}$, respectively in an Intevac Gen II system. ${ }^{21,22}$ The GaN was grown at $1040{ }^{\circ} \mathrm{C}$ on $\mathrm{Al}_{2} \mathrm{O}_{3}$ substrates by Metal Organic Chemical Vapor Deposition (MOCVD). Total layer thicknesses were $\sim 1 \mu \mathrm{m}$ for the AlN and $\mathrm{InN}$, and 2-3 $\mu \mathrm{m}$ for the $\mathrm{GaN}$.

The samples were patterned with Apiezon wax and etched in a Plasma-Therm ICP 790 system. The temperature of the back-side cooled chuck was held at $23{ }^{\circ} \mathrm{C}$. The if chuck power was varied between 50 and $350 \mathrm{~W}$, and ICP source power between 300 and $1000 \mathrm{~W}$. The process pressure was held constant at $5 \mathrm{mTorr}$, while the total flow rate of 
$\mathrm{IBr} / \mathrm{Ar}$ or $\mathrm{ICl} / \mathrm{Ar}$ gas was $15 \mathrm{sccm}$. Etch rates were calculated from stylus profilometry measurements of the etched samples after the removal of the mask material. The error of these measurements is approximately $\pm 5 \%$. Surface morphology was examined by atomic force microscopy (AFM) system operating in tapping mode with Si tip. The selectivity was calculated for InN over AlN and GaN.

\section{RESULTS AND DISCUSSION}

Figure 1 shows the effect of plasma composition on etch rates of $\operatorname{InN}, \mathrm{AlN}$ and $\mathrm{GaN}$ in $\mathrm{IBr} / \mathrm{Ar}$ and $\mathrm{ICl} / \mathrm{Ar}$ discharges at $5 \mathrm{mTorr}, 750 \mathrm{~W}$ source power and $250 \mathrm{~W} \mathrm{rf}$ chuck power. The etch rates of $\operatorname{InN}$ and AlN are relatively independent of plasma composition in $\mathrm{IBr}$ (Fig. 1, top) and $\mathrm{ICl}$ (middle) plasmas over a broad composition range, indicating the etch mechanism is dominated by physical sputtering. The dc bias voltages increased with increasing etch gas concentrations, resulting in decrease in ion flux entering the sheath layer (Fig.1, bottom). The ion flux at the sheath edge was calculated using a global self-consistent model developed for the ICP etching system. ${ }^{23}$ The increase in dc biases or decrease in ion flux can be explained by the fact that compared to pure Ar discharges, additional collisional energy losses (which include excitation of vibrational and rotational energy levels, molecular dissociation and negative ion formation ${ }^{24}$ ) are present with $\mathrm{IBr}$ and $\mathrm{ICl}$. The decrease in ion flux also implies an increase in concentrations of neutral species such as $\mathrm{Cl}, \mathrm{Br}$ and $\mathrm{I}$. The etch rate of $\mathrm{GaN}$ increased up to $66.7 \% \mathrm{IBr}$ and remained almost constant at higher concentration (Fig. 1, top). By contrast the etch rate steadily increased with increasing ICl concentration in the 
ICl/Ar plasma (middle). This result indicates that etching of $\mathrm{GaN}$ in both chemistries is more attributed to chemical etching by increased concentrations of reactive neutrals than ion-assisted sputtering.

The effect of ICP source power on etch rates, dc bias voltages, and ion fluxes at the sheath edge are shown in Fig 2 for $\mathrm{IBr} / \mathrm{Ar}$ (top) and ICV/Ar discharges (middle) at 5 mTorr. Flow rates of etch gases were $2 \mathrm{sccm} \mathrm{IBr}$ or $\mathrm{ICl}$ and $13 \mathrm{sccm}$ Ar. During these runs the rf chuck power was held constant at $250 \mathrm{~W}$, which results in a decrease in dc bias as the ICP power increased. Lower dc biases were attributed mainly to increased ion density at higher ICP powers (bottom). InN again showed higher etch rates than AIN and $\mathrm{GaN}$. The high etch rates for InN are similar to the previously reported results observed for $\mathrm{InP}$ where efficient ion-assisted desorption of $\mathrm{InCl}_{\mathrm{x}}$ occurs under ICP conditions. ${ }^{25}$ The etch rates of InN, AlN and GaN increased up to $500 \mathrm{~W}$, and remained relatively constant at higher source power. The increase in etch rate with increasing the source power is due to the higher concentration of reactive species in the plasma, suggesting a reactant-limited regime, and to higher ion flux to the substrate surface. The relatively constant etch rate with further increase of the ICP power is attributed to the competition between ion-assisted etch reaction and ion-assisted desorption of the reactive species at the substrate surface prior to etch reactions.

Figure 3 shows the effect of rf chuck power on the etch rates, dc bias, and ion flux at the sheath edge. Etch rates for all materials increased in both $\mathrm{IBr}$ (top) and $\mathrm{ICl}$ (middle) discharges as the rf power or the ion-bombarding energy increased. InN showed higher etch rates again than GaN and AlN: maximum etch rate of $\operatorname{InN}$ is $\sim 6,000 \AA / \mathrm{min}$. The increase in etch rate with the chuck power can be attributed to enhanced sputter 
desorption of etch products as well as physical sputtering of the $\mathrm{InN}$ surface. The dc bias voltage increased monotonically with increasing rf chuck power from 50 to $350 \mathrm{~W}$, but the ion flux at the sheath edge increased slightly (Fig.3, bottom). This is because the main role of the chuck power is to increase the ion-bombarding energy. The effect of the $\mathrm{rf}$ power on etch rate (or etch yield) and ion flux at the sheath edge in the ICP system is described in detail elsewhere. ${ }^{23,26}$ It is also interesting to see that the magnitude of etch rate is in the order of bond energies, $\operatorname{InN}(7.72 \mathrm{eV})<\mathrm{GaN}(8.92 \mathrm{eV})<\mathrm{AlN}(11.52 \mathrm{eV}){ }^{27}$

The effect of reactor pressure on etch rate, etch yield (defined as number of atoms etched per incident ion ${ }^{23}$ ), dc bias and ion flux in ICl/Ar plasmas is shown in Fig. 4. During these experiments the source and chuck powers were held constant at $750 \mathrm{~W}$ and $250 \mathrm{~W}$, respectively. InN showed a maximum etch rate at $15 \mathrm{mTorr}$ and decreased with further increasing pressure, while the etch rate of $\mathrm{GaN}$ increased up to $10 \mathrm{mTorr}$ and decreased thereafter (top). It is also seen that the etch rate of AIN was almost independent of the pressure. The increased etch rates of $\operatorname{InN}$ and $\mathrm{GaN}$ with pressure indicates that etching is limited by mass transfer of reactive gas species at the lower pressures. However, as the pressure increases further, the etch rate decreases due to either lower ion flux to the substrate surface or to redeposition of etch products. Etch yield data are shown in the lower part of the figure. The higher dc voltages or lower ion fluxes at higher pressures were attributed to increased collisional recombination which decreased the plasma ion density.

Etch morphology was examined using AFM for GaN samples etched at $750 \mathrm{~W}$ ICP power, $250 \mathrm{~W}$ rf chuck power and $5 \mathrm{mTorr}$ in $2 \mathrm{sccm} \mathrm{ICl} / 13 \mathrm{sccm}$ Ar and $2 \mathrm{sccm}$ $\mathrm{IBr} / 13 \mathrm{sccm}$ Ar discharges, respectively and the results are shown in Fig. 5 with the rms 
roughness. It is seen that $\mathrm{IBr} / \mathrm{Ar}$ chemistry (bottom) shows somewhat better morphology than ICl/Ar (top), resulting in overall mirrorlike smoothness in both chemistries.

In order to reduce the currently high contact resistance in GaN-based heterostructure field transistors, ${ }^{28}$ and eventually heterojunction bipolar transistors, it is expected that InN-based contact layers will be necessary, ${ }^{29-30}$ in analogy to InGaAs on GaAs. In such a case, the ability to selectively etch InN relative to the other nitrides will be crucial. Figures 6 to 8 show some selectivity data as functions of plasma composition, rf power, and ICP power in IBr- and ICl-based plasmas, respectively. The effect of plasma composition showed an overall trend of decrease in selectivities for $\operatorname{InN}$ over AlN and over $\mathrm{GaN}$ as the concentrations of $\mathrm{IBr}$ and $\mathrm{ICl}$ increase (Fig. 5). However, the selectivity of InN over AlN showed maximum values depending on ICP source power (Fig. 6) and rf chuck power (Fig. 7), while that of $\mathrm{InN}$ over $\mathrm{GaN}$ increased overall as the source and chuck powers increased. The maximum values of selectivity obtained in this work were $\sim 30$ for InN/AlN and $\sim 14$ for InN/GaN. It is also clearly seen that the selectivities of InN over $\mathrm{AlN}$ in both of $\mathrm{IBr} / \mathrm{Ar}$ and $\mathrm{ICl} / \mathrm{Ar}$ discharges are greater than those of InN over GaN.

\section{SUMMARY AND DISCUSSION}

Etching of GaN, AlN and InN has been carried out with $\mathrm{ICV} / \mathrm{Ar}$ and $\mathrm{IBr} / \mathrm{Ar}$ chemistries in an Inductively Coupled Plasma discharge. The effects of plasma composition, ICP source power, rf chuck power and pressure on etch rate, etch yield, dc bias and ion flux at the sheath edge were examined. The etch rates of InN and AIN are 
relatively independent of plasma composition, while GaN showed increased etch rates with etch gas concentrations. Etch rates for all materials in the ICl- and IBr-based discharges increased with increasing the rf chuck power, indicating that higher bombarding energies are more efficient in enhancing sputter desorption of etch products. The etch rates increased up to $500 \mathrm{~W}$ ICP power and saturated for higher powers, while $\mathrm{GaN}$ and $\mathrm{InN}$ showed maximum etch rates with increasing pressure. The maximum selectivities obtained in this work were $\sim 30$ for InN/AlN and $\sim 14$ for InN/GaN, respectively. The selectivities of $\mathrm{InN}$ over $\mathrm{AlN}$ in both of $\mathrm{IBr} / \mathrm{Ar}$ and $\mathrm{ICl} / \mathrm{Ar}$ discharges are greater than those of $\mathrm{InN}$ over $\mathrm{GaN}$.

\section{ACKNOWLEDGEMENTS}

The work at UF is partially supported by a DARPA/EPRI grant MDA-972-98-10006 (E. R. Brown/J. Melcher). YBH gratefully acknowledges the support of the Korea Research Foundation for Faculty Research Abroad and KOSEF through the Automation Research Center. Sandia is a multi-program laboratory operated by Sandia Corporation, a Lockheed-Martin company, for the US Department of Energy under contract DEAC94AL-85000. 


\section{REFERENCES}

1. R. J. Shul, G. B. McClellan, S. A. Casalnuova, D. J. Rieger, S. J. Pearton, C. Constantine, C. Barrat, R. F. Karlicek, Jr., C. Tran, and M. Schurman, Appl. Phys. Lett., 69, 1119 (1996).

2. R. J. Shul, in GaN and Related Materials, ed. S. J. Pearton (Gordon and Breach, N. Y., 1997).

3. H. P. Gillis, D. A. Choutov, and K. P. Martin, JOM, 48, 50 (1996).

4. I. Adesida, A. Mahajan, E. Andideh, M. A. Khan, D. T. Olsen, and J. N. Kuznia, Appl. Phys. Lett., 63, 2777 (1993).

5. M. E. Lin, Z. F. Fan, Z. Ma, L. H. Allen, and H. Morkoc, Appl. Phys. Lett., 64,887 (1994).

6. H. Lee, D. B. Oberman, and J. S. Harris, Jr., Appl. Phys. Lett., 67, 1754 (1995).

7. W. Pletschen, R. Niegurch, and K. H. Bachem, Proc. Symp. Wide Bandgap Semiconductors and Devices, Vol. 95-21 (Electorchemcal Society, Pennington, N. J., 1995), 241.

8. S. J. Pearton, C. R. Abernathy, and F. Ren, Appl. Phys. Lett., 64, 2294 (1994).

9. L. Zhang, J. Ramer, J. Brown, K. Zhang, L.F. Lester, and S. D. Hersee, Appl. Phys. Lett., 68, 367 (1996).

10. R. J. Shul, R. D. Briggs, S. J. Pearton, C. B. Vartuli, C. R. Abernathy, J. W. Lee, C. Constantine, and C. Barratt, Mat. Res. Soc. Symp. Proc., 449, 969 (1997).

11. H. Cho, C. B. Vartuli, S. M. Donovan, C. R. Abernathy, S. J. Pearton, R. J. Shul, and C. Constantine, J. Vac. Sci. Technol. A, 16, 1631 (1998). 
12. H. Cho, C. B. Vartuli, S. M. Donovan, K. D. Mackenzie, C. R. Abernathy, S. J. Pearton, R. J. Shul, and C. Constantine, J. Electron. Mat., 27, 166 (1998).

13. S. Nakamura, in GaN and Related Materials, ed. S. J. Pearton (Gordon and Breach, N. Y. 1997).

14. O. Aktas, Z. Fan, S. N. Mohammad, A. Botcharev, and H. Morkoc, Appl. Phys. Lett., 69,25 (1996).

15. M. A. Khan, J. N. Kuznia, M. S. Shur, C. Eppens, J. Burm, and W. Schaff, Appl. Phys. Lett., 66, 1083 (1995).

16. Y. F. Wu, B. P. Keller, S. Keller, D. Kapolnek, S. D. Den Baars, and U. K. Mishra, IEEE Electron. Dev. Lett., 17, 455 (1996).

17. M. A. Khan, Q. Chen, M. S. Shur, B. T. McDermott, J. A. Higgins, J. Burm, W. Schaff, and L. F. Eastman, Electron. Lett., 32, 357 (1996).

18. Y. T. Wu, S. Keller, P. Kozodoy, B. P. Keller, P. Parikh, D. Kapolnek, S. P. Denbaars, and U. K. Mishra, IEEE Electron. Dev. Lett., 18, 290 (1997).

19. C. B. Vartuli, S. J. Pearton, J. W. Lee, J. D. Mackenzie, C. R. Abernathy, and R. J. Shul, J. Vac. Sci. Technol. B, 15, 98 (1997).

20. J. W. Lee, J. Hong, E. S. Lambers, and S. J. Pearton, J. Vac. Sci. Technol. B, 15,652 (1997).

21. C. R. Abernathy, J. Vac. Sci. Technol. A, 11, 869 (1993).

22. C. R. Abernathy, Mat. Sci. Eng. Rep., R14, 203 (1995).

23. Y. B. Hahn and S. J. Pearton (to be published).

24. M. A. Lieberman and A. J. Lichtenberg, Principles of Plasma Discharges and Materials Processing, John Wiely \& Sons Inc., N. Y. (1994). 
25. J. W. Lee, J. Hong, and S. J. Pearton, Appl. Phys. Lett., 68, 847 (1996).

26. Y. B. Hahn, D. C. Hays, S. M. Donovan, C. R. Abernathy, J. Han, R. J. Shul, H. Cho, K. B. Jung, and S. J. Pearton, J. Vac. Sci. Technol. A, submitted (1998).

27. CRC Handbook of Chemistry and Physics, $70^{\text {th }}$ Ed., eds. R. C. Weast, D. R. Lide, M. J. Astle, and W. H. Beyer (CRC Press Inc., Boca Raron, FL, 1989).

28. J. Burm, K. Chu, W. J. Schaff, L. F. Eastman, M. A. Khan, Q. Chen, J. W. Yang, and M. S. Shur, IEEE Electron. Dev. Lett., 18, 141 (1997).

29. S. M. Donovan, K. D. MacKenzie, C. R. Abernathy, S. J. Pearton, F. Ren, K. Jones, and M. Cole, Appl. Phys. Lett., 70, 2592 (1997).

30. F. Ren, C. R. Abernathy, S. J. Pearton, and P. W. Wisk, Appl. Phys. Lett., 64, 1508 (1994).

31. F. Ren, R. J. Shul, C. R. Abernathy, S. N. G. Chu, J. R. Lothian, and S. J. Pearton, Appl. Phys. Lett., 66, 1503 (1995). 


\section{Figure Captions}

Figure 1. Effect of plasma composition on etch rates in $\mathrm{IBr} / \mathrm{Ar}$ (top) and ICV/Ar (middle) plasma chemistries, and dc bias and ion flux at the sheath (bottom).

Figure 2. Effect of ICP source power on etch rates in $\mathrm{IBr} / \mathrm{Ar}$ (top) and ICV/Ar (middle) plasma chemistries, and dc bias and ion flux at the sheath (bottom).

Figure 3. Effect of rf chuck power on etch rates in $\mathrm{Br} / \mathrm{Ar}$ (top) and ICVAr (middle) plasma chemistries, and dc bias and ion flux at the sheath (bottom).

Figure 4. Effect of if pressure on etch rates in ICl/Ar (top) plasma chemistry, and dc bias and ion flux at the sheath (bottom).

Figure 5. AFM scans for GaN etched in ICV/Ar (top) and IBr/Ar (bottom) plasmas.

Figure 6. Effect of $\mathrm{IBr}$ (top) and ICl (bottom) concentrations on the selectivity for InN over GaN and AIN (750 W source power, $250 \mathrm{~W}$ rf chuck power, $5 \mathrm{mTorr}$ ).

Figure 7. Effect of ICP source power on the selectivity for $\operatorname{InN}$ over GaN and AlN (750 $\mathrm{W}$ source power, $5 \mathrm{mT}$ Torr). 
Figure 8. Effect of rf chuck power on the selectivity for $\mathrm{InN}$ over GaN and AlN ( $250 \mathrm{~W}$ rf chuck power, 5 mTorr). 

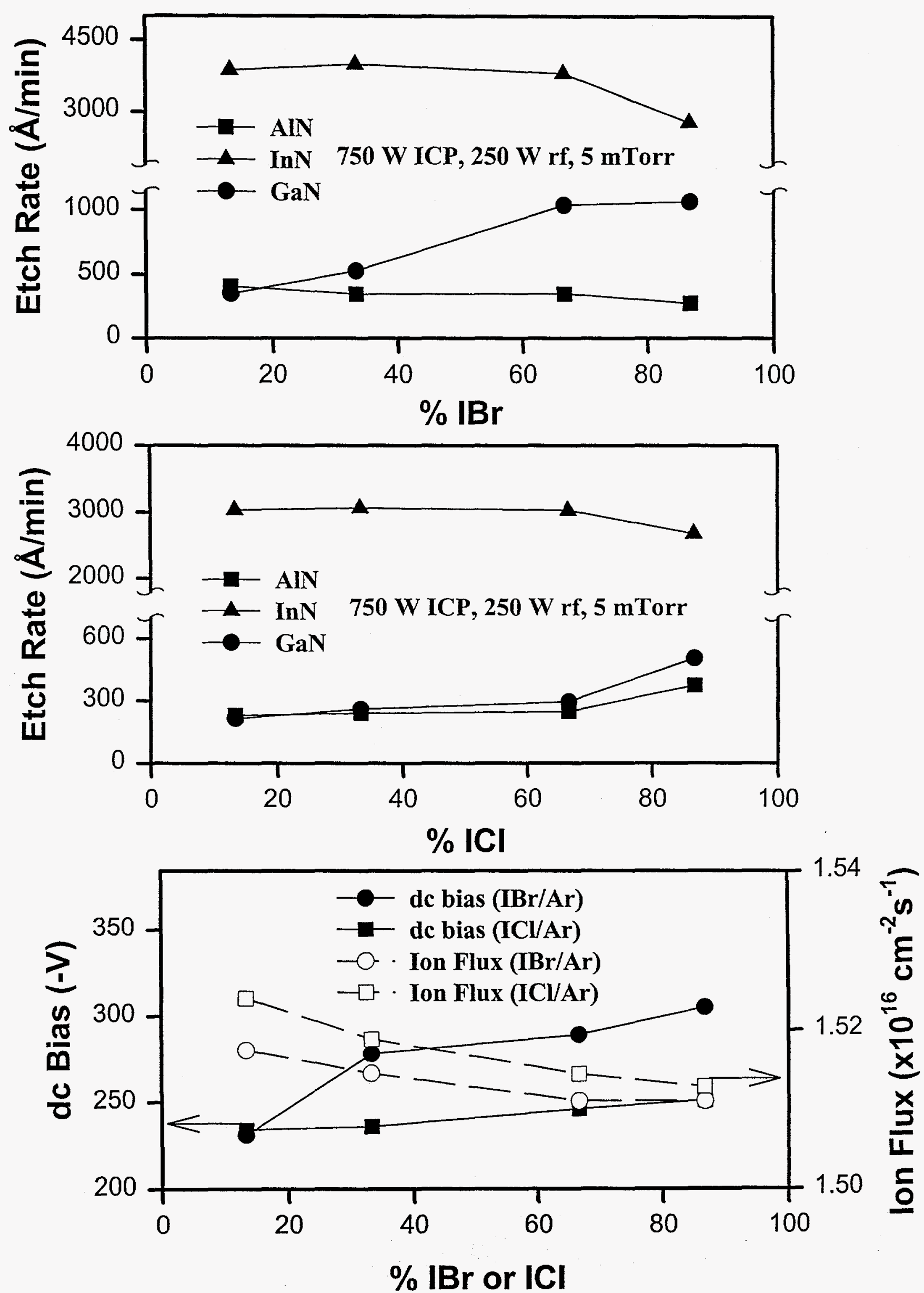

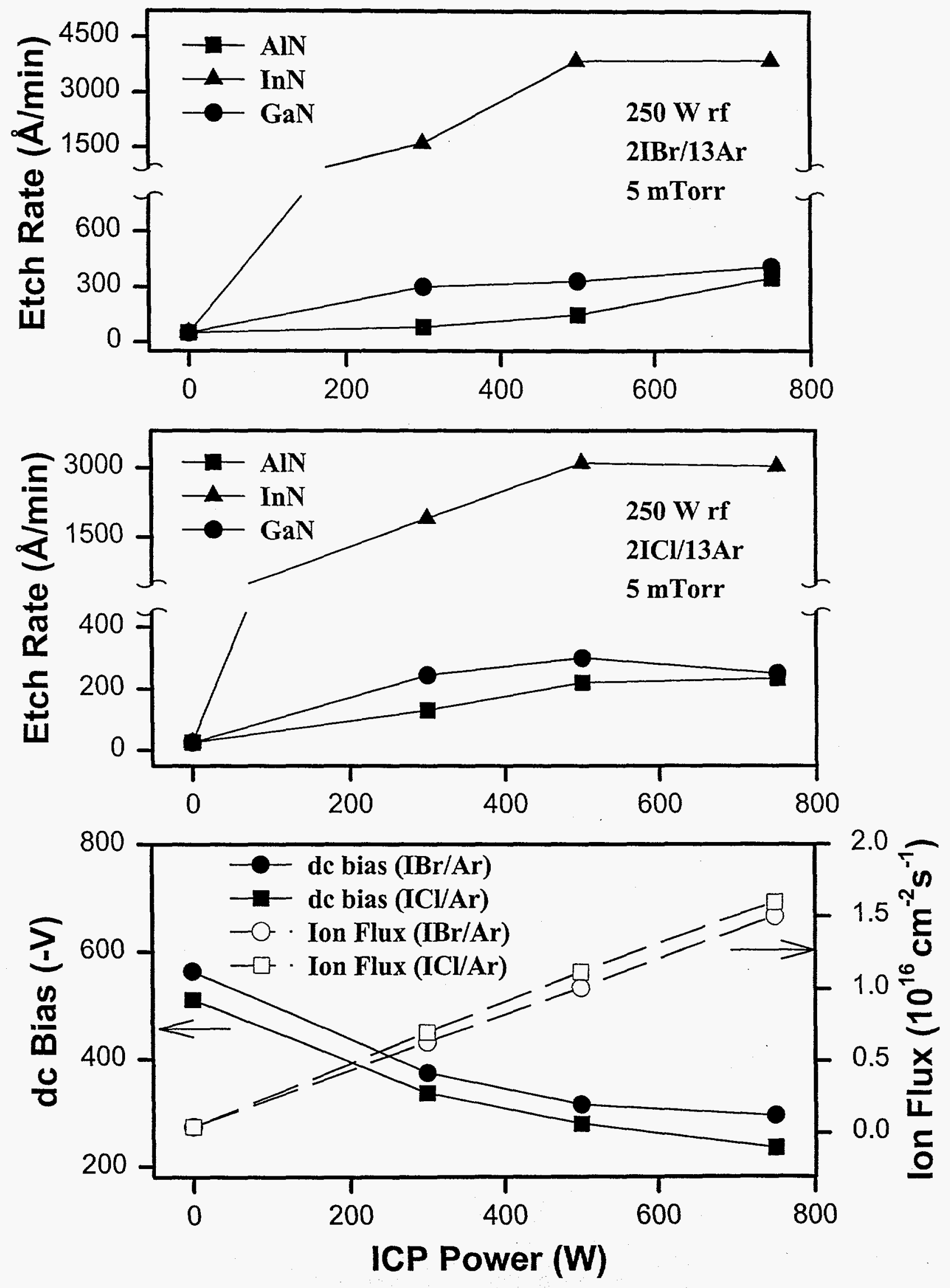

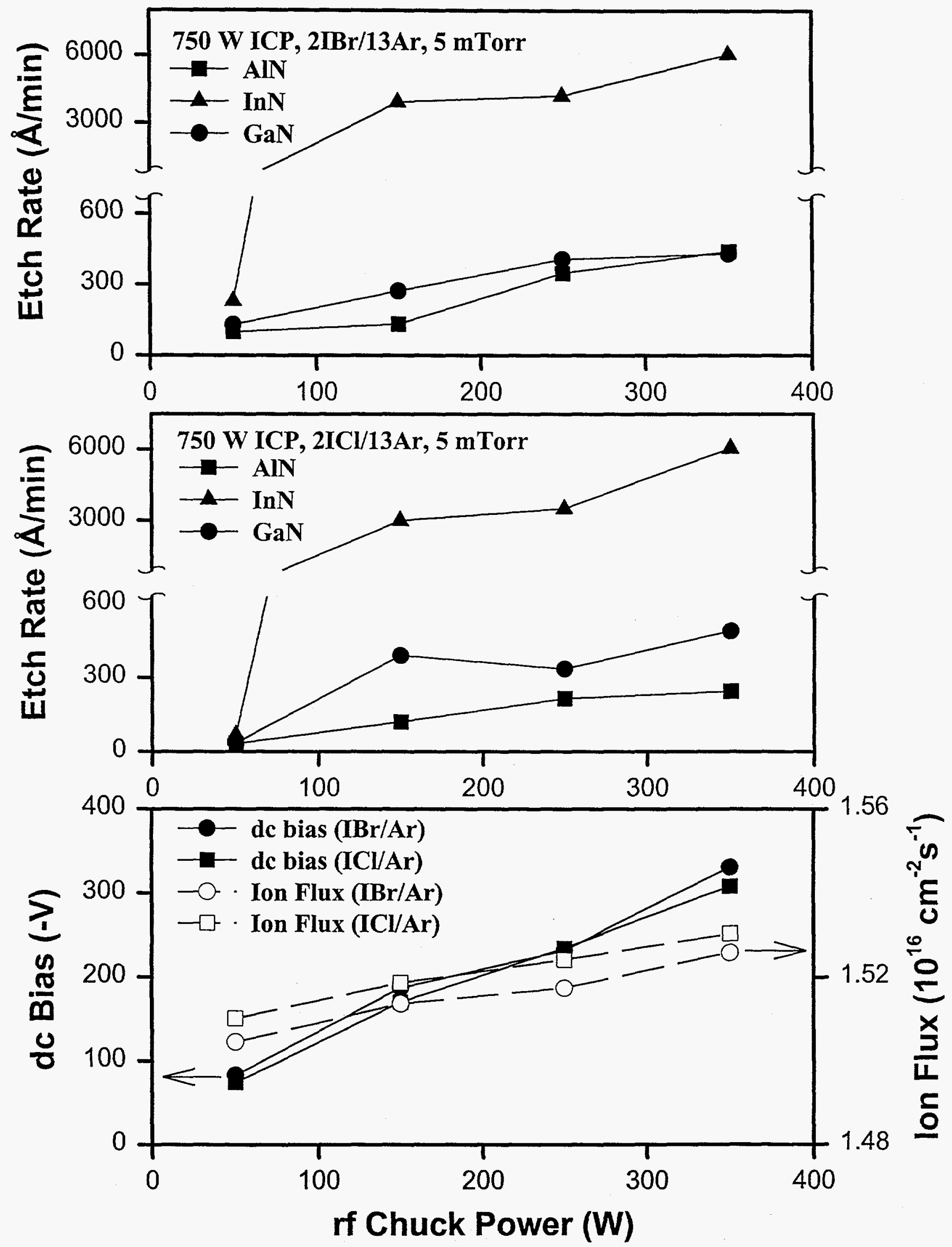

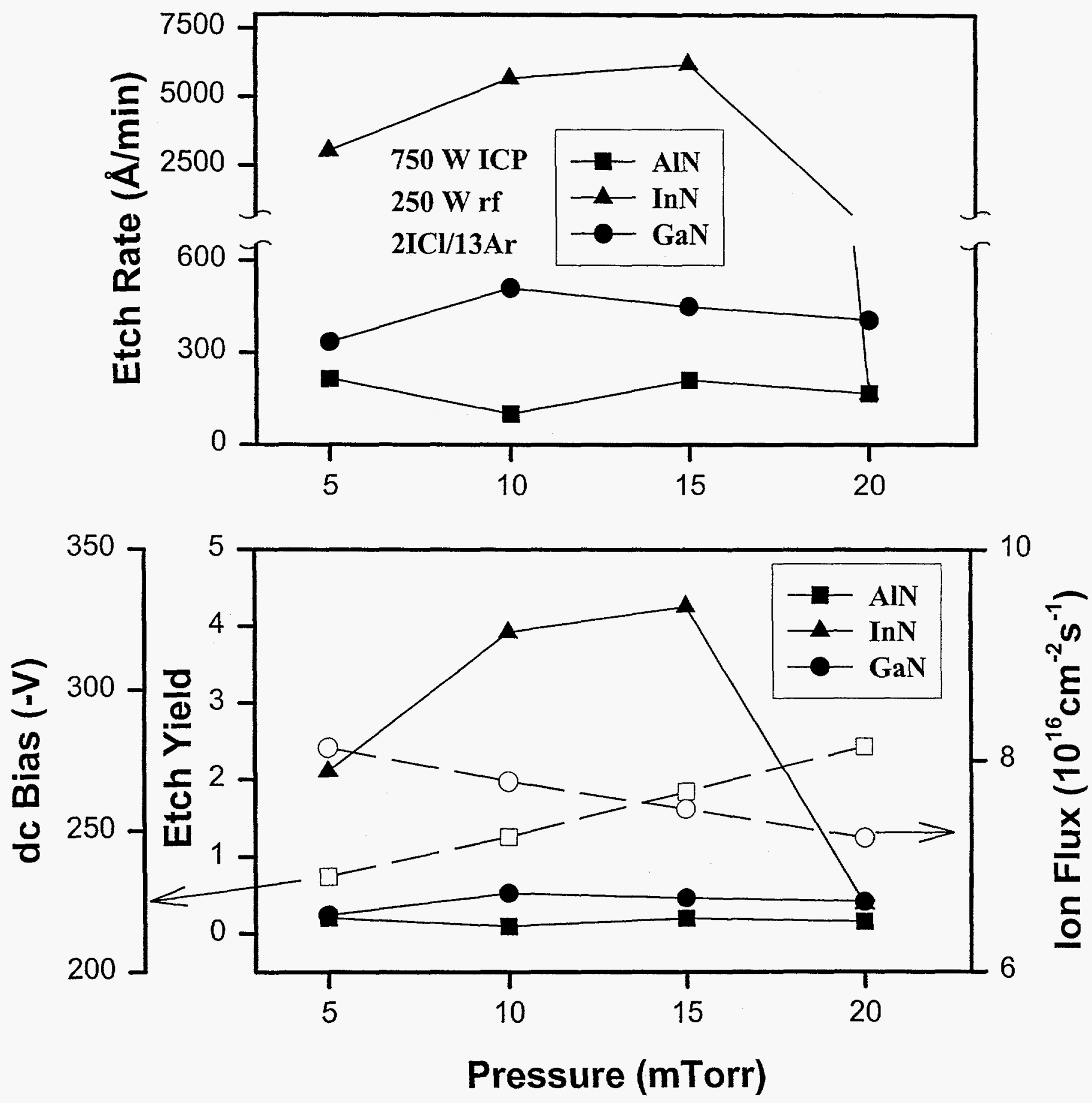


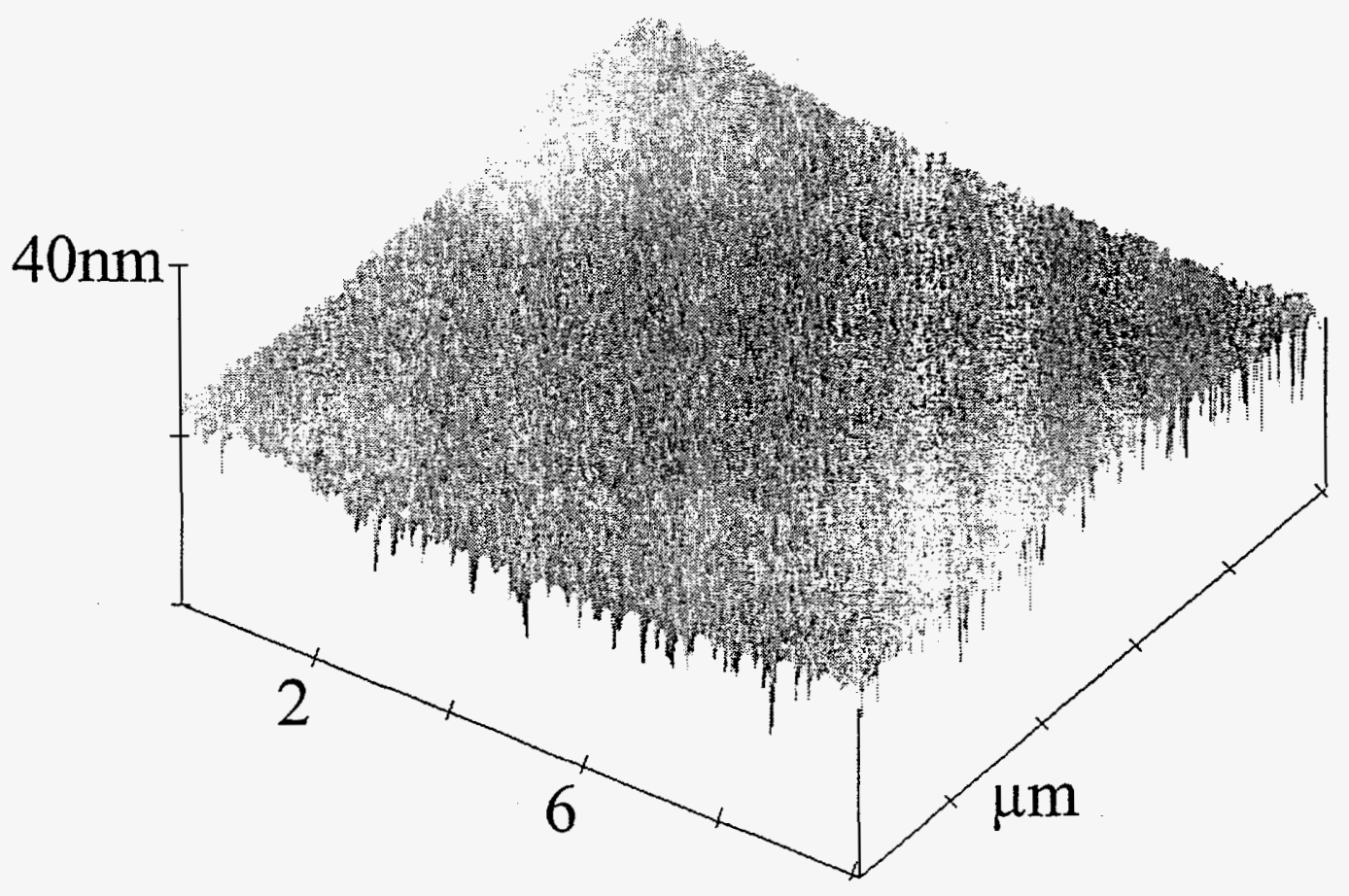

\title{
$2 \mathrm{ICl} / 13 \mathrm{Ar}$ \\ RMS Roughness $=2.3 \mathrm{~nm}$
}

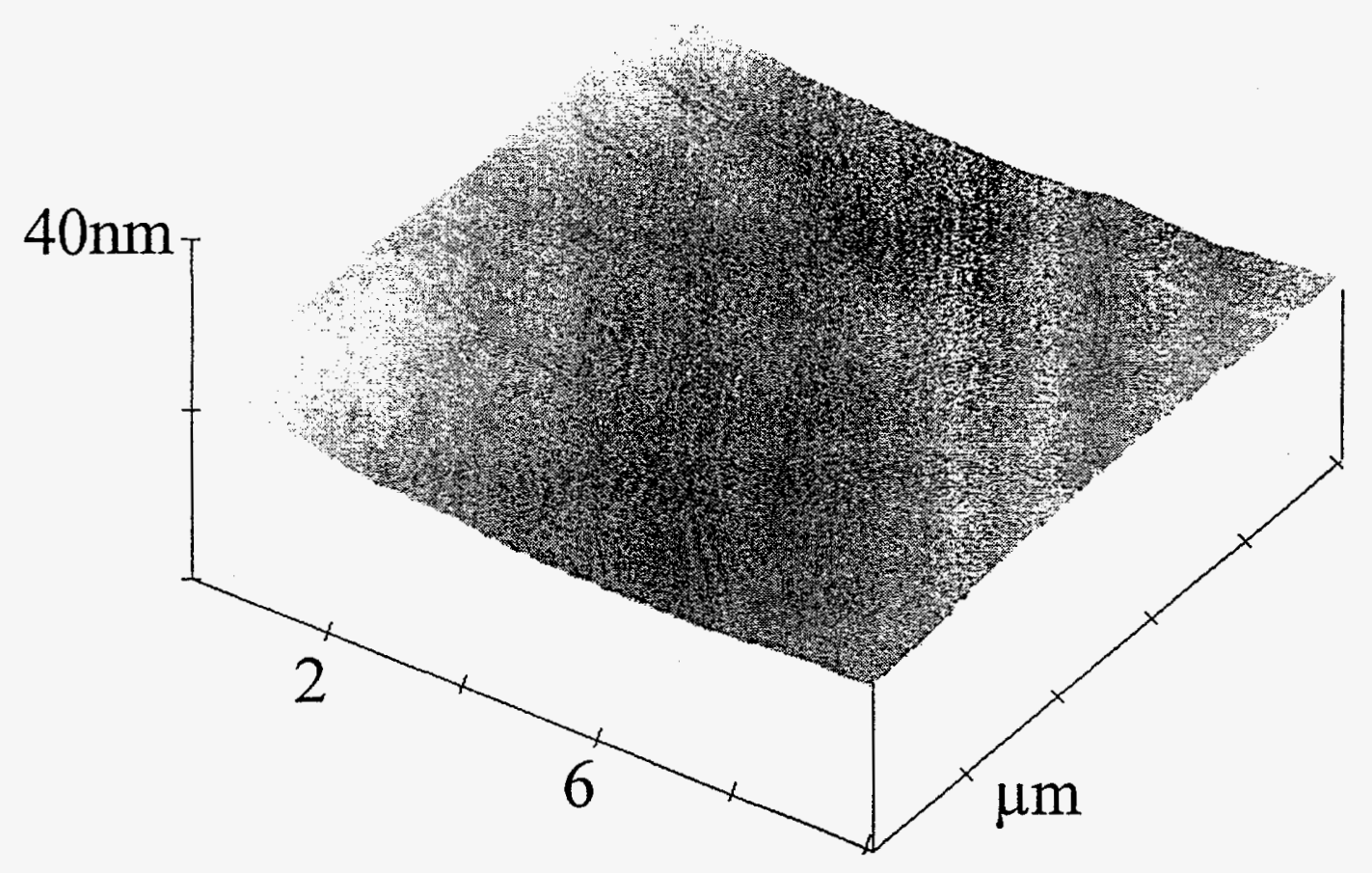

\author{
$2 \mathrm{IBr} / 13 \mathrm{Ar}$ \\ RMS Roughness $=1.1 \mathrm{~nm}$
}



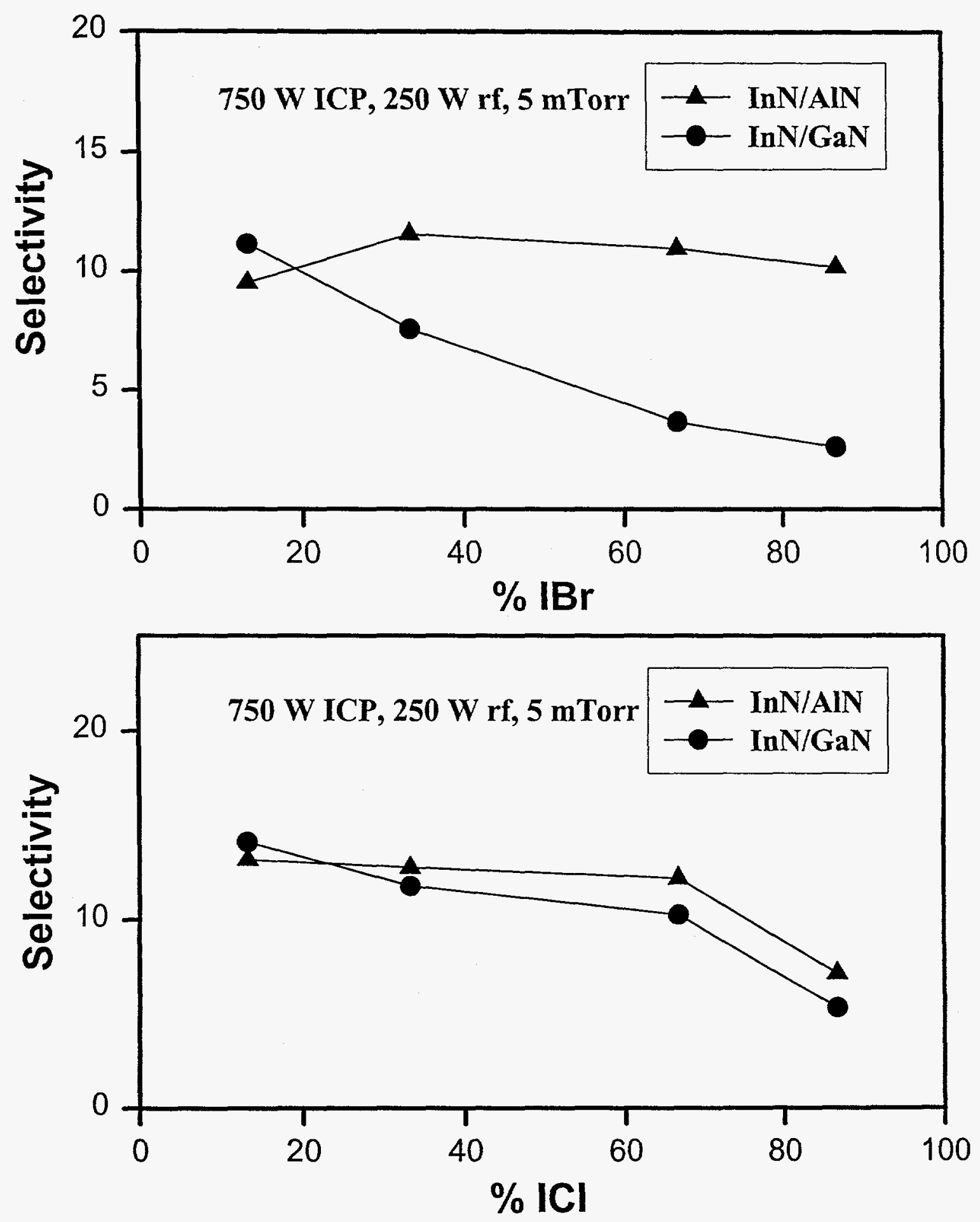

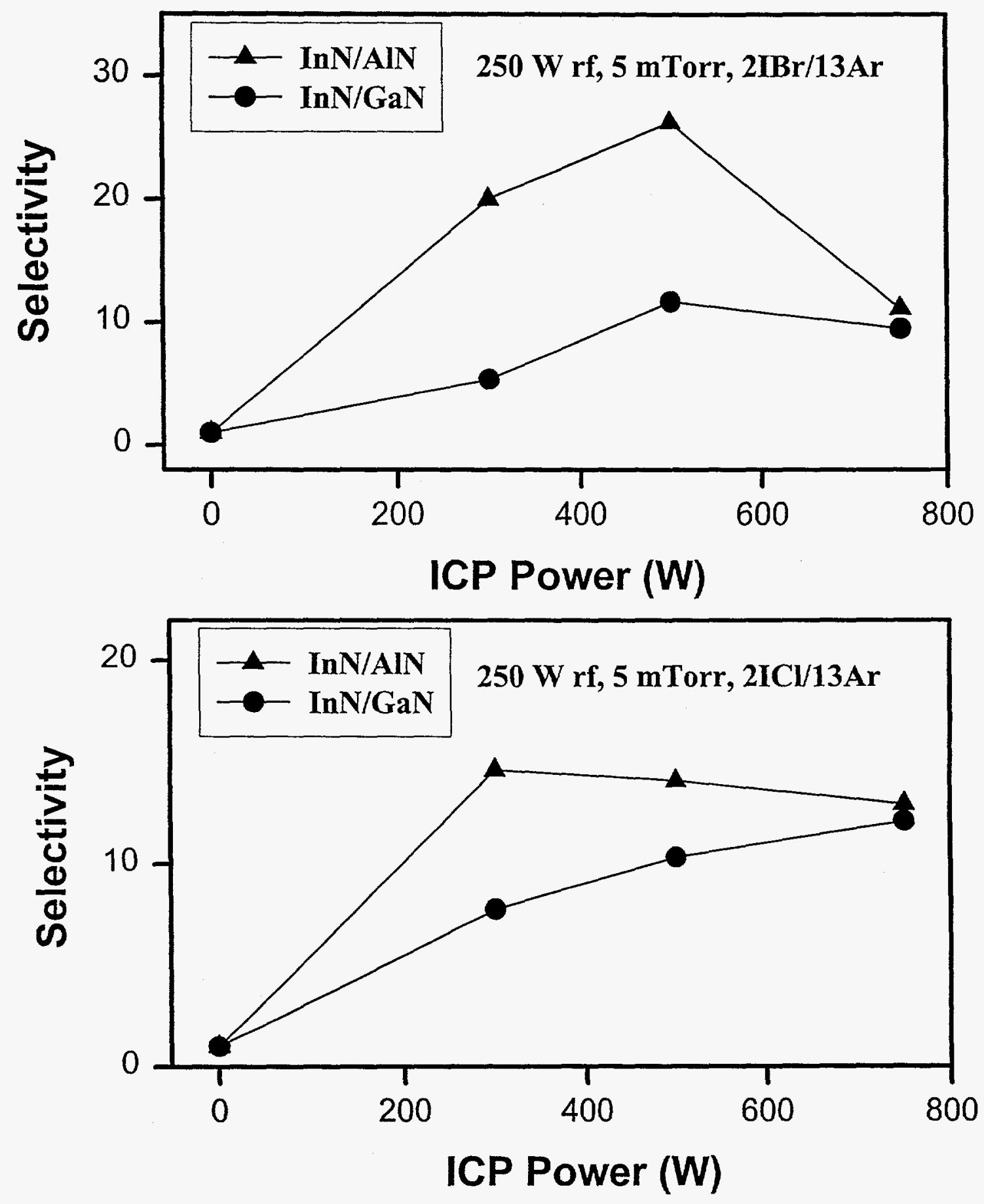

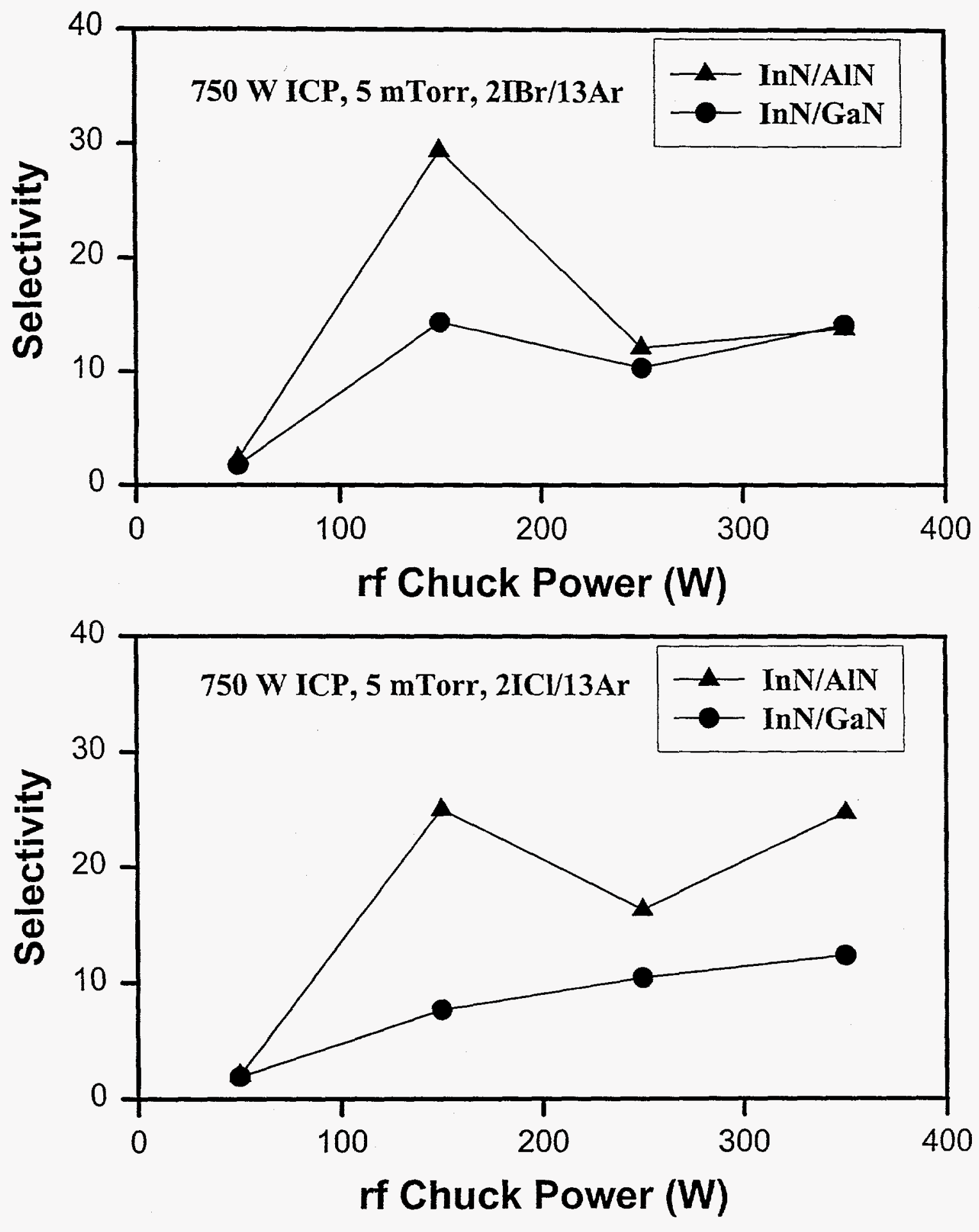